\title{
A INCLUSÃo DE ALUNOS SURDOS EM UM INSTITUTO FEDERAL: PONTOS E CONTRAPONTOS
}

\author{
THE INCLUSION OF DEAF STUDENTS IN A FEDERAL INSTITUTE: POINTS AND \\ COUNTERPOINTS
}

LA INCLUSIÓN DE ESTUDIANTES SORDOS EN UN INSTITUTO FEDERAL: PUNTOS Y CONTRAPUNTOS

\section{Cristiane Rodrigues de Freitas \\ (iD) 9}

Mestrado em Educação

Profissional e Tecnológica (IFAM)

Pedagoga do Instituto Federal do

Amazonas (IFAM)

cristianesrr@hotmail.com

\section{Cirlande Cabral da Silva \\ (iD) 9}

Pós doutorado em Educação em

Ciência

Professor do Instituto Federal do

Amazonas (IFAM)

Professor do PPG em Educação

Profissional e Tecnológica (IFAM)

e do PPG em Educação em

Ciências e Matemática

(REAMEC/UEA)

cirlandecabral@gmail.com

\begin{abstract}
Resumo
A inclusão de alunos surdos no contexto da escola regular ainda se apresenta como um grande desafio. O objetivo deste trabalho foi analisar como ocorre o processo de inclusão dos alunos surdos nos Cursos Técnicos do Instituto Federal do Amazonas - Campus Manaus Centro. Participaram da pesquisa 06 alunos surdos, 06 docentes, 04 pedagogas, 01 representante do NAPNE e 02 Intérpretes e Tradutores de Libras. Utilizou-se para a coletada de dados as entrevistas, observações (registro em diário de campo) e rodas de conversa. A análise dos dados foi feita através da Análise de conteúdo com a obtenção de 03 categorias finais. As categorias obtidas indicam que o processo de inclusão naquele Instituto foi iniciado e está em andamento (mesmo que de forma incipiente) mas ainda precisa de ajustes e reparos para o seu fortalecimento através da transformação de ações inclusivas parciais ou articuladas.
\end{abstract}

Palavras-chave: Educação inclusiva. Educação de surdos. Categorias analíticas.

Recebido em: 13 de janeiro de 2021.

Aprovado em: 12 de abril de 2021.

Como citar esse artigo (ABNT):

FREITAS, Cristiane Rodrigues de; SILVA, Cirlande Cabral da. A inclusão de alunos surdos em um Instituto Federal: pontos e contrapontos. Revista Prática Docente, v. 6, n. 1, e021, 2021. http://doi.org/10.23926/RPD.2021.v6.n1.e021.id976 


\section{Abstract}

The inclusion of deaf students in the context of regular school is still a major challenge. The objective of this work was to analyze how the process of inclusion of deaf students in the Technical Courses of the Federal Institute of Amazonas - Campus Manaus Centro occurs. 06 deaf students, 06 teachers, 04 pedagogues, 01 NAPNE representative and 02 Libras Interpreters and Translators participated in the research. Interviews, observations (record in a field diary) and conversation circles were used for data collection. The analysis of the data was made through Content Analysis with the obtaining of 03. The categories obtained indicate that the process of inclusion in that Institute has started and is underway (even if in an incipient way) but still needs adjustments and repairs for the its strengthening through the transformation of inclusive or partial actions.

Keywords: Inclusive education. Deaf education. Analytical categories.

\section{Resumen}

La inclusión de estudiantes sordos en el contexto de la escuela regular sigue siendo un gran desafío. El objetivo de este trabajo fue analizar cómo ocurre el proceso de inclusión de estudiantes sordos en los Cursos Técnicos del Instituto Federal Amazonas Campus Manaus Centro. En la investigación participaron 06 estudiantes sordos, 06 profesores, 04 pedagogos, 01 representante de NAPNE y 02 intérpretes y traductores de Libras. Para la recopilación de datos se utilizaron entrevistas, observaciones (registro en un diario de campo) y círculos de conversación. El análisis de los datos se realizó a través de Análisis de Contenido con la obtención de 03. Las categorías obtenidas indican que el proceso de inclusión en ese Instituto se ha iniciado y está en marcha (aunque de forma incipiente) pero aún necesita ajustes y reparaciones para el su fortalecimiento a través de la transformación de acciones inclusivas o parciales.

Palabras clave: Educación inclusiva. Educación para sordos. Categorías analíticas. 


\section{INTRODUÇÃO}

A inclusão de alunos surdos no contexto da escola regular, ainda se apresenta como um grande desafio, pois as leis da inclusão das pessoas com deficiência (PCDs) não tem dado a garantia total de uma prática inclusiva no cotidiano escolar. Existe uma série de questões que ainda precisam ser alcançadas pelas instituições de ensino e profissionais da educação para que esses alunos realmente tenham um processo educativo equânime e condizente.

A presente pesquisa é um recorte da dissertação intitulada "A inclusão de alunos surdos no Instituto Federal de Educação, Ciência e Tecnologia do Amazonas: e agora, o que fazer?" (apresentada no Programa de Pós-Graduação em Educação Profissional e Tecnológica profEPT/IFAM, no ano 2019) que ocorreu durante minha vivência como pedagoga, quando atuava junto às turmas do Curso Técnico em Química na forma integrada do Instituto Federal de Educação, Ciência e Tecnologia (IFAM), campus Manaus Centro (CMC), ao receber alunos surdos e ao compartilhar dúvidas e preocupações externadas por alguns colegas pedagogos e também professores sobre como realizar o acompanhamento pedagógico desses alunos de maneira inclusiva em um contexto educacional na forma de ensino integrado.

O IFAM/CMC é uma instituição que oferece à sociedade amazonense a oportunidade de cursar o ensino médio integrado que é uma forma de ensino que permite ao aluno estudar, ao mesmo tempo, o ensino médio e realizar um curso técnico que proporcionará uma profissão a esse indivíduo, após três anos de estudo. Assim, realizar um curso técnico integrado exige a estadia desse aluno na escola durante o dia todo para o cumprimento de toda a carga horária prevista no Projeto Pedagógico de Curso (PPC).

Nesse sentido, o IFAM como uma escola de Educação Profissional e Tecnológica que trabalha com o ensino médio integrado e que deve seguir as mudanças que ocorrem nas políticas educacionais brasileiras, em destaque às políticas de concretização da educação escolar dentro de uma perspectiva inclusiva, assegurada pelo poder público em todos os níveis e modalidades do sistema educacional, precisou adaptar-se a essa nova proposição de inclusão das pessoas com deficiência (PCDs) nas classes regulares de ensino.

Diante desse contexto, a efetivação das políticas de regulamentação da inclusão escolar de pessoas com deficiência no ensino regular é uma realidade (ainda que incipiente) dentro das instituições de ensino que têm recebido esse público em seu contexto educacional e, por conseguinte, precisa organizar e planejar suas práticas e ações pedagógicas dentro da perspectiva de uma educação realmente inclusiva. 
Para tanto, o processo educacional inclusivo deve favorecer a permanência, o crescimento, a estabilização e o fortalecimento de relações interpessoais harmoniosas por meio de um planejamento inclusivo criterioso, pois os procedimentos adotados refletirão nesse aluno, proporcionando resultados positivos ou negativos e na sua permanência e êxito dentro da instituição de ensino.

Diante desse cenário de políticas escolares na perspectiva inclusiva, algumas pesquisas foram feitas como a de Santos (2015) que identificou quais eram as práticas pedagógicas de inclusão escolar desenvolvidas por professoras dos anos iniciais de uma escola pública, concluindo que não é um processo fácil, pois requer persistência e força de vontade de todos os atores envolvidos e ainda recursos financeiros e humanos.

Barbosa (2007) teve o propósito de identificar, reunir e analisar os instrumentos legais que garantiam a inclusão do surdo no sistema regular de ensino público, concluindo que houve avanço na educação do surdo devido à garantia dos direitos das pessoas com deficiência por meio da inclusão, mas o referido autor percebeu que ainda é necessário que os objetivos de uma escola inclusiva para o aluno surdo sejam concretizados efetivamente na prática da realidade educativa brasileira.

Miller Junior (2013) estudou a inclusão de surdos no Ensino Médio, constatando que é necessária uma reorganização urgente da política de educação inclusiva para os surdos que leve em consideração a cultura e a identidade surda.

No Estado do Amazonas, destacamos três pesquisas realizadas com essa temática. A primeira delas, a de Santos (2017) que realizou uma investigação sobre a educação de surdos com enfoque no discurso da inclusão educacional, produzido por surdos e ouvintes, verificando que os discursos sobre o desenvolvimento da educação de surdos são diferentes entre a comunidade surda e as políticas de educação inclusiva do governo, mas destaca que a referida política contribuiu com a ruptura da cultura hegemônica ouvinte.

A segunda pesquisa é a de Sá (2011) que investigou os avanços e retrocessos a partir da política nacional de educação na perspectiva inclusiva, no contexto das escolas de surdos na cidade de Manaus, concluindo que houve progressos concernente à perspectiva bilíngue para surdos e divulgação da libras para os professores, mas também ocorreram retrocessos devido ao fechamento ou descaracterizações de algumas escolas para surdos, além da inclusão de surdos em escolas regulares totalmente despreparadas no atendimento específico desse público. 
A terceira pesquisa é a de Souza (2015) que teve como objetivo analisar o projeto político-pedagógico escolar para verificar sua consonância com as políticas educacionais voltadas para a implementação da educação Bilíngue de surdos. O referido autor concluiu que as escolas estudadas asseguravam a entrada dos alunos surdos de acordo com a legislação, mas detectou que os Projetos Pedagógicos de Cursos (PPC) não continham ações e estratégias básicas para atender às diferenças de aprendizagem dos surdos no processo educativo.

Dentro desse contexto, o IFAM por meio do Núcleo de Atendimento a Pessoas com Necessidades Educacionais Especiais (NAPNE), criado por meio da Portaria $\mathrm{n}^{\mathrm{o}} 180$ GDG/CEFET-NA/02 de 15/04/2002 e estruturado nos Institutos Federais de Educação (IFES) pelo Programa Educação, Tecnologia e Profissionalização para Pessoas com Necessidades Especiais na Rede Federal de Educação Tecnológica (TEC NEP) vem auxiliar a inclusão das pessoas com deficiência nos cursos da Rede Federal de Ensino em parceria com instituições municipais e estaduais de ensino.

Atualmente visando a organização dos procedimentos das PCDs no IFAM foi aprovada Resolução no 31 CONSUP/IFAM de 06/06/2018 que regulamenta o procedimento para o atendimento das pessoas com deficiência. Este é um documento que viabiliza a padronização de ações por meio de orientações acerca dos passos para um atendimento igualitário, pautado nas necessidades específicas dos discentes. O referido documento fala da importância da constituição de uma comissão multiprofissional, além de destacar as atribuições da mesma e disponibilizar 04 (quatro) formulários para utilização no processo de acompanhamento dos alunos.

Assim, a compreensão de como ocorre a inclusão de alunos surdos no contexto educacional do IFAM poderá trazer inúmeras contribuições na implementação e desenvolvimento de políticas inclusivas, estruturação de práticas pedagógicas inclusivas na sala de aula, conscientização da comunidade escolar por meio de formações adequadas, além de melhorias no desenvolvimento de processos inclusivos na instituição estudada e nas demais instituições que poderão utilizar o estudo a ser realizado em seus contextos educativos.

Dessa forma, frente ao panorama apresentado o objetivo dessa pesquisa foi analisar como ocorre o processo de inclusão dos alunos surdos nos Cursos Técnicos de Nível Médio na forma integrada do IFAM/CMC e sua importância para a retenção e desenvolvimento pedagógico do discente surdo. 


\section{EDUCAÇÃo ESPECIAL E INCLUSIVA NO BRASIL}

A educação especial, no Brasil, assim como no mundo foi constituída por princípios assistencialistas e clínicos, características de dimensões segregadoras, sendo organizada e separada do sistema comum de ensino. Kassar (2011) relata que no Brasil a educação das pessoas com deficiência foi construída separadamente das pessoas sem deficiência, assim a educação especial teve um campo de atuação tão específico que acarretou um sistema paralelo de ensino que praticamente não mantinha relação com a educação comum. Dessa maneira, a educação das PCDs ocorria em locais separados com o enfoque no ensino excludente que não promovia a acessibilidade necessária à inclusão dessas pessoas na sociedade, situação essa perpetuada até o momento do surgimento de políticas públicas que proporcionaram a transformação desse cenário.

Os primeiros vestígios da criação de legislações específicas para a educação especial no Brasil que encontramos na história surgem na época do império, Sigolo; Guerreiro; Cruz (2010) descrevem que foi por meio do Decreto Imperial $n^{\circ} .1 .426$, de 12 de setembro de 1854 que foi criada a Fundação do Imperial Instituto dos Meninos Cegos (atual Instituto Benjamin Constant -IBC), em seguida através da Lei $n^{\circ} .839$, de 26 de setembro de 1857 ocorreu a criação do atual Instituto Nacional de Educação de Surdos - INES na época, Fundação do Imperial Instituto dos Surdos-Mudos.

Durante um período considerável do século XX, a ideia de uma educação especializada configurou a organização do sistema de ensino referente ao atendimento das pessoas com deficiência, mas algumas mudanças começaram a surgir por meio de algumas legislações como a Lei 4.024/61 que começa a considerar que as PCDs possuíam o direito a uma educação com aspectos igualitários dentro do sistema regular de ensino, ao tratar sobre a educação de excepcionais em seu artigo 88: "a educação de excepcionais deve, no que for possível, enquadrar-se no sistema geral de educação, a fim de integrá-los na comunidade" (BRASIL, 1961).

Essa possível "integração", possibilitada pela lei no 4.024/61, sofreu um retrocesso com a lei $n^{\circ} 5.692 / 71$ ao trazer em seu artigo $9^{\circ}$ o caráter de uma educação especialista que segrega ao invés de incluir. Assim, o que se percebe são políticas desenvolvidas e configuradas para o tratamento das deficiências em detrimento de um ensino que considere os aspectos individuais dos educandos em consonância com um planejamento adequado para um atendimento igualitário a esse aluno no sistema regular de ensino, conforme destacado no documento Política 
Nacional de Educação Especial na Perspectiva da Educação Inclusiva (BRASIL, 2008, p.7): "Nesse período não se efetiva uma política pública de acesso universal à educação, permanecendo a concepção de "políticas especiais" para tratar da educação de alunos com deficiência $[\ldots]$ '..

O ano de 1988 traz, por meio da Constituição Federal Brasileira, o amparo legal para as pessoas com deficiência iniciarem um novo ciclo pela busca da consolidação de seus direitos dentro da sociedade, ao estabelecer nos artigos 206 e 208 uma educação igualitária e o atendimento educacional na rede regular de ensino, conforme destacado no documento da Política Nacional de Educação Especial (2008):

A Constituição Federal de 1988 traz como um dos seus objetivos fundamentais "promover o bem de todos, sem preconceitos de origem, raça, sexo, cor, idade e quaisquer outras formas de discriminação" (art. $3^{\circ}$ inciso IV). Define, no artigo 205, a educação como um direito de todos, garantindo o pleno desenvolvimento da pessoa, o exercício da cidadania e a qualificação para o trabalho. No seu artigo 206, inciso I, estabelece a "igualdade de condições de acesso e permanência na escola", como um dos princípios para o ensino e, garante, como dever do Estado, a oferta do atendimento educacional especializado, preferencialmente na rede regular de ensino (art. 208) (BRASIL, 2008, p.7).

Após a promulgação da Constituição Federal de 1988, surgiram outros documentos e legislações que foram criados dentro de uma perspectiva de educação inclusiva, onde destacase o Estatuto da Criança e Adolescência (ECA) sancionado pela Lei $n^{\circ} 8.069 / 90$ e a Lei $n^{\circ}$ 9.394/61 que apresenta a educação especial como uma modalidade de educação.

Lima e Neta (2017) destacam a lei no 9.394/96 que trouxe a consolidação da legislação sobre educação inclusiva no Brasil, favorecendo ainda a criação de outros documentos que fortaleceram a viabilização da educação inclusiva no cenário educacional brasileiro, como por exemplo: as Diretrizes Nacionais para a Educação Especial na Educação Básica (BRASIL, 2001) que orientam sobre a responsabilidade e a organização das escolas no atendimento aos alunos com necessidades educativas específicas e o Plano Nacional de Educação que traz metas para as matrículas na educação especial.

Mediante a documentação legal que favorece a inclusão e traz os desafios de uma educação escolar inclusiva na sociedade brasileira, entramos no século XXI, com princípios legais favoráveis à construção de um novo percurso que favoreça a quebra do paradigma de que as pessoas com deficiência devem ficar isoladas de todos, principalmente no ambiente escolar, como podemos verificar no artigo $2^{\circ}$ da Resolução CNE/CEB nº 2/2001 (BRASIL, 2001):

Os sistemas de ensino devem matricular todos os alunos, cabendo às escolas organizar-se para o atendimento aos educandos com necessidades educacionais 
especiais, assegurando as condições necessárias para uma educação de qualidade para todos (BRASIL, 2001).

Dessa forma, defender a ideia de que no Brasil essa mudança seria imediata ou entendida realmente numa perspectiva inclusiva seria uma atitude precipitada, pois a educação numa perspectiva inclusiva requer uma série de mudanças no processo educativo de forma prática. Portanto, a promulgação de uma lei (ou de várias) para a sociedade não garante mudanças efetivas na realidade cotidiana das escolas. Dessa forma, concorda-se com Pacheco (2016) quando diz que será necessária uma nova maneira de ser da escola para torná-la acessível, por meio do respeito aos direitos individuais de cada pessoa. Assim, para isto são necessárias mudanças técnicas, metodológicas e didáticas que deveriam ocorrer junto com a questão da acessibilidade arquitetônica, pedagógica, comunicacional.

Em outras palavras, é necessário garantir a aplicabilidade da legislação por meio de adequações necessárias ao sistema de ensino e de ações conjuntas do Governo, escola e sociedade em geral, a fim de que a proposta de escolas inclusivas conte com o envolvimento de todos. Concorda-se com Santos (2015) quando afirma que o acesso aos conteúdos, conceitos, valores e experiências materializados no processo de ensino-aprendizagem devem ser realizados de forma equitativa, sem restrições ou tabus, pois somente assim obterá o êxito tão almejado.

Portanto, o processo inclusivo precisa do apoio de toda a escola e inicia com o agente de portaria, docentes, colegas de turmas, direção, enfim todos que fazem parte da instituição de ensino.

\section{Procedimentos Metodológicos}

\subsection{TIPO DE PESQUISA E LÓCUS DA INVESTIGAÇÃO}

Nesta pesquisa, utilizou-se a abordagem qualitativa por considerar que ela proporciona a obtenção de significados, de forma sistemática e profunda além de considerar a perspectiva histórica e social do momento em que ocorre a análise.

Foi utilizado a pesquisa do tipo estudo de caso, considerada por Creswell (2014) como uma abordagem qualitativa que permite ao pesquisador explorar um caso ou múltiplos casos contemporâneos que no decorrer do tempo, através de uma coleta de dados profunda e a utilização de diversas fontes de informação como por exemplo: observações, entrevistas, material audiovisual, documentos e relatórios, contribuirá no relato da descrição de um caso e/ou temas do caso. 
A pesquisa foi realizada no Instituto Federal de Educação, Ciência e Tecnologia do Amazonas (IFAM) que atualmente conta com catorze campi e um campus avançado em vários municípios do Estado do Amazonas. Em Manaus encontram-se três campi: Campus Manaus Distrito Industrial, Campus Manaus Zona Leste e Campus Manaus Centro no qual desenvolvemos a referida pesquisa.

O IFAM possui um Núcleo de Atendimento às Pessoas com Necessidades Educativas Especiais sistêmico (NAPNE) e os NAPNEs Campi que atendem aos alunos com necessidades educativas especiais que chegam à instituição. O NAPNE do Campus Manaus Centro desenvolve o trabalho com os alunos surdos, por meio do acompanhamento dos Tradutores e Intérpretes e de Libras (TILPS), sala de atendimento para o acompanhamento e reforço escolar das dificuldades escolares dos alunos, orientações aos docentes, pais e demais membros comunidade escolar, além de oferecer cursos de libras.

\subsection{Sujeitos da Pesquisa}

A pesquisa foi desenvolvida com a participação de 06 alunos surdos dos Cursos Técnicos de Nível Médio na forma integrada do campus Manaus Centro (CMC) e teve como critérios que os estudantes fossem ingressantes e utilizassem a libras para se comunicarem. Durante a pesquisa, realizou-se uma entrevista individual com cada discente surdo, observada e registrada em diário de campo. Durante a observação, utilizou-se um diário de campo onde registrou-se as práticas inclusivas realizadas na sala de aula com cada um dos alunos entrevistados, a relação aluno surdo-professor, aluno surdo-alunos ouvintes e a prática docente em sala de aula.

Após esse momento realizou-se um encontro com todos os alunos surdos, onde desenvolveu-se uma atividade que envolvia a elaboração de dois desenhos, tendo em vista o aluno surdo ser primordialmente visual. Acredita-se que, através dos desenhos, os alunos conseguiriam expressar de forma mais clara o que pensavam acerca da temática levantada. Assim, o primeiro desenho deveria demonstrar o que eles entendiam como inclusão escolar e o segundo (desenho) deveria demonstrar como era a inclusão escolar no IFAM.

Convidou-se também para participar dessa investigação 06 docentes que ministravam aula para os alunos surdos, sendo 03 professores da cultura geral e 03 da área técnica, a fim de identificar as práticas pedagógicas desenvolvidas no contexto das salas de aula. Com esse professores fez-se uma entrevista, além de acompanhar algumas aulas para realizar observações 
e registros escritos em um diário de campo sobre a dinâmica e estrutura das aulas nas salas de aulas inclusivas, onde os alunos pesquisados estavam matriculados.

As pedagogas que atendiam os alunos pesquisados também foram convidadas para participar da pesquisa, sendo um total de quatro, sendo que três delas atuavam diretamente nos departamentos de ensino do campus Manaus Centro (CMC) e uma atuava na direção de ensino.

Em relação ao NAPNE convidou-se um representante daquele núcleo para participar de uma entrevista, devido a sua importância nas políticas e ações inclusivas desenvolvidas no Campus Manaus Centro.

A pesquisa ainda teve a participação de dois Intérpretes e Tradutores de Libras que atuavam no acompanhamento dos alunos. Estes foram entrevistados e observados no acompanhamento dos referidos alunos, seja no ambiente da sala de aula ou nas demais atividades que acompanhamos na escola durante a pesquisa.

\subsection{InSTRUMentos de COLETA de DAdos}

Esta investigação utilizou alguns instrumentos de coleta de dados que ajudaram a delinear a pesquisa. Entre eles utilizou-se a entrevista por meio de perguntas semiestruturadas que oportunizaram reorganizá-las e reformulá-las, pois acredita-se que por meio do contato presencial pode-se (por meio da percepção visual e atitudinal expressadas nas repostas verbais e gestuais) identificar dados importantes para o desenvolvimento da pesquisa. Segundo Gil (2009), a entrevista é uma técnica eficiente e flexível que permite ao entrevistador obter dados diversos e de forma mais profunda, pois se for bem conduzida possibilitará o esclarecimento até de situações inconscientes do comportamento humano, além de permitir que as perguntas sejam adaptadas durante a entrevista.

Lakatos e Marconi (2010) destacam a entrevista e a observação como técnicas de observação direta intensiva, destacando a observação como uma técnica que permite pesquisar dados, examinar fatos e identificar situações por meio dos sentidos que as pessoas não têm consciência, mas norteiam o seu comportamento.

Nesse sentido, utilizou-se a observação sistemática, na qual foi planejado os dias que visitaríamos as salas de aula dos discentes surdos para vivenciarmos o cotidiano escolar em que os referidos alunos estavam inseridos, além de esquematizar os principais pontos que observaríamos, a fim de não perder nenhum dado relevante para a pesquisa. De acordo com Silva (2001) a observação sistemática deve ser planejada a fim de se obter propósitos 
estabelecidos, que sejam respondidos, além de proporcionar a obtenção de dados de alguns aspectos da realidade.

A observação foi realizada nos tempos de aula dos docentes participantes para obtenção de dados por meio de registro escrito em um diário de campo que consideramos um instrumento importante para posterior consulta das anotações das práticas inclusivas identificadas. Gil (2009) destaca que o pesquisador deve definir o que irá observar e a forma como irá registrar e organizar as informações coletadas.

Assim, utilizou-se o diário de campo como instrumento de registro que nos permitiu identificar posteriormente informações importantes e detalhadas coletados durante as visitas na sala de aula. Oliveira (2007) destaca que o diário é um lugar onde encontramos importantes discussões relevantes, por meio da consulta, ao registro das observações. Dessa forma, a sua utilização foi fundamental, pois além de nos possibilitar novas reflexões sobre o problema pesquisado, nos auxiliou na análise dos dados. Porlán (2004) destaca-o como fundamental, devido aos registros metódicos e detalhados das observações durante as aulas.

A escolha pela utilização do diário de campo trouxe inúmeras possibilidades, pois viabilizou o registro das informações de forma apropriada na análise das percepções, questionamentos e preocupações levantados durante a pesquisa, por isso registrou-se as nossas observações em três partes: a observação dos alunos surdos na sala de aula, a observação da prática docentes com os alunos surdos na sala de aula e a interação dos colegas ouvintes e discentes surdos em sala de aula, destacando o dia, a turma, a disciplina e o docente cuja aula acompanhamos conforme o planejamento proposto para a pesquisa.

Em relação ao encontro coletivo realizou-se uma roda de conversa. Para Moura e Lima (2014) a roda de conversa é um momento singular de partilha e que ocorre em um ambiente propício para o diálogo, onde todos se sintam à vontade para falar e escutar por meio da interação com o outro, sendo um método de participação coletiva sobre a temática proposta.

Na roda de conversa, reuniu-se os alunos surdos participantes da pesquisa e foi proposto, por meio de duas perguntas, a criação de dois desenhos (como citado anteriormente) que expressassem a percepção individual de cada um, primeiramente sobre o que é inclusão escolar e depois sobre como se dava a inclusão escolar no IFAM. A roda de conversa foi iniciada por meio de um vídeo da Língua Brasileira de Sinais (libras) que explicava sobre a inclusão escolar do surdo e em seguida explicou-se como seria a dinâmica dessa atividade. Entregou-se a eles 
uma folha com duas imagens e duas frases para os alunos desenharem e em seguida explicassem os seus desenhos.

\subsection{InSTRUMENTO de ANÁliSE dE DAdOS}

Após o levantamento dos dados, partiu-se para a análise e interpretação das informações coletadas, por meio da análise de conteúdo de Bardín (2016). Segundo Silva e Fossá (2015, p.2) “[...] é uma técnica de análise das comunicações, que irá analisar o que foi dito nas entrevistas ou observado pelo pesquisador. Na análise do material, busca-se classificá-los em temas ou categorias que auxiliam na compreensão do que está por trás dos discursos".

Segundo Bardín (2016), atualmente a análise de conteúdo é designada por várias técnicas de análises das comunicações que utiliza procedimentos sistemáticos. Assim, por meio da descrição dos conteúdos e mensagens dos indicadores infere-se sobre os conhecimentos, referente às condições de produção/recepção das mensagens.

Esse tipo de análise apresenta três polos cronológicos, onde o primeiro deles é a Préanálise considerada uma etapa organizacional, intuitiva, mas também um momento de operacionalização e sistematização das ideias iniciais. Nessa perspectiva, iniciou-se com uma leitura flutuante, em seguida foi escolhido os documentos que deveriam compor o corpus da pesquisa seguindo os critérios de representatividade, exclusividade, homogeneidade e pertinência (proposto por Bardín, 2016) para então proceder com a formulação das hipóteses, referenciação dos índices e elaboração dos indicadores (recorte, categorização, codificação) até chegar à preparação do material.

A segunda fase é a exploração do material. Nesta fase, o pesquisador irá minuciosamente aplicar sistematicamente as decisões tomadas codificando e categorizando os dados da pesquisa, como o autor descreve: “...Essa fase, longa e fastidiosa, consiste essencialmente em operações de codificação, decomposição ou enumeração, em função de regras previamente formuladas" (BARDIN, 2016, p.131)

A terceira fase é o tratamento dos resultados obtidos na interpretação de forma rigorosa, a fim de obter resultados significativos, propor inferências e interpretações dos objetivos previstos. Segundo o Bardín (2016) o analista deve tratar os resultados brutos de forma a tornálos significativos e falantes, a fim de propor inferências para então realizar interpretações, conforme os objetivos previstos ou acerca de descobertas inesperadas. Essas três fases serão mais discutidas no tópico a seguir. 


\section{Resultados e Discussões}

Com o término da coleta de dados, passamos para a próxima etapa da pesquisa que foi a análise de dados. Para isso, procedeu-se o início da análise por meio da apropriação da técnica de análise de conteúdo que subsidiou, conforme descrito anteriormente através de três polos cronológicos que foram a pré-análise, a exploração do material e o tratamento dos resultados, a inferência e a interpretação dos dados.

Assim, iniciou-se a pré-análise dos dados por meio da organização de todo o material coletado que foram: i) as entrevistas (um total de 19) que foram gravadas e depois transcritas; ii) os diários de campo (um total de 13), e iii) 01 encontro final com os alunos surdos que também resultou em um dos diários de campo. Após esse primeiro momento, começou-se uma leitura flutuante de todos os dados a fim de sistematizar o processo de construção do corpus da pesquisa embasados nas regras de exaustividade, representatividade, homogeneidade e pertinência conforme descrito por Bardin (2016).

Em seguida, iniciou-se a exploração do material com a construção de operações de codificação por meio do recorte dos textos em unidades de registros que se deram em função da triangulação dos resultados observados de todo o material coletado. Finalmente utilizou-se as rodas de conversas para a triangulação dos dados, conforme a Figura 1 abaixo.

Figura 1 - Representa a triangulação dos dados da pesquisa para a realização da análise de conteúdo

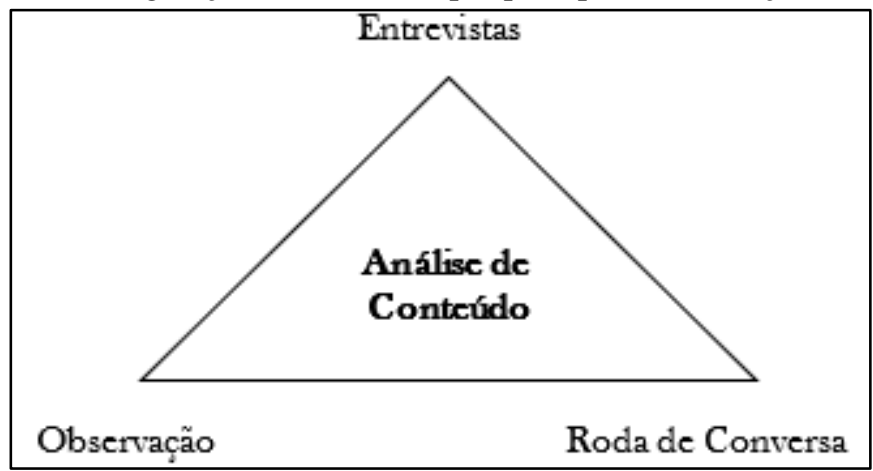

Fonte: Freitas (2020).

As unidades de registro se configuraram no recorte de frases e parágrafos das observações descritas no diário de campo, das entrevistas e da descrição das rodas de conversa com os alunos surdos.

Dessa maneira, selecionou-se as unidades de registros e as aglutinamos de forma temática, alinhadas com o objetivo da pesquisa com o intuito de verificar e analisar os dados coletados (para preservamos a identidade dos participantes da pesquisa, utilizou-se para os alunos, professores, pedagogos e intérpretes os números naturais, professor 1, professor 2 , 
aluno, 1, aluno 2, pedagogo 1, pedagogo 2 e assim sucessivamente com todos, menos com a Gestão, onde teremos apenas Gestão 1). Para elucidar as unidades de registro selecionadas e a semelhança dos códigos, destaca-se alguns excertos relevantes no quadro 1 (abaixo).

\section{Quadro 1 - Unidades de Registro 1: Processo Inclusivo dos alunos surdos}

Percepção dos participantes da pesquisa sobre a inclusão escolar
Aluno surdo 1 - "A escola inclusiva é diferente, o aluno surdo está em meio a muitos alunos
ouvintes, ele tem uma mistura de sensações, ele se sente triste, ele se sente isolado [...]".
Intérprete 1 - "[...] inclusão escolar é uma forma, né, de trabalhar com os alunos surdos numa
perspectiva junto com os alunos ouvintes, assim como os alunos que possuem outras deficiências, né,
juntamente com os alunos que não possuem deficiência”.
Pedagoga 3 - "Bem, inclusão escolar no meu entendimento envolve vários fatores, não é só você
receber o aluno com dificuldade ou de aprendizagem ou dificuldade é, vamos dizer, física, mas é
receber esse aluno e está preparado pra receber esse aluno com material adequado e a infraestrutura
adequada é uma equipe adequada preparada pra receber esse aluno".
Professor 6 - “A inclusão, na minha opinião, seria [...] pessoas diferentes ou com capacidades
diferentes estando junto na mesma, num mesmo ambiente né tentando aprender sem ter ambientes
separado, né, pra isso".
A visão da inclusão aliada à língua de sinais e a língua portuguesa
Pedagoga 1 - “... eles não vêm com essa alfabetização em língua portuguesa de uma forma
satisfatória pra dar prosseguimento aos estudos e é uma formação aí desde a base já está
comprometida".
Pedagoga 2 - "Realmente essa questão da comunicação eles reclamam muito e aí depois que se
resolveu junto ao NAPNE essa questão dos interpretes ficou melhor, mas no nosso departamento, os
professores é... eles têm pedido isso com muita frequência, que é a falta que o aluno tem... que o aluno
surdo, ele não foi alfabetizado em português, então o quê que eles sempre deixam como indicativo lá
pro departamento, é que se o aluno tivesse dentro do instituto o apoio pra se alfabetizar em português,
ele ia vencer as barreiras inclusive das disciplinas técnicas”.
Professor 1 - "A minha maior dificuldade é não saber libras, isso é fundamental... é não sei
libras [...]”.

$$
\text { Fonte: Freitas (2020). }
$$

Nos excertos abaixo (quadro 2) os participantes da pesquisa levantam questões não somente sobre a formação docente, mas a capacitação de todos os profissionais que atendem aos alunos surdos, visando à inclusão efetiva dos mesmos no ambiente escolar. Ainda são destacados assuntos de acessibilidade comunicacional e arquitetônica, o NAPNE como estratégia e política de inclusão no IFAM/CMC, sugestões de treinamentos sistemáticos e alfabetização em português.

Quadro 2 - Unidades de Registro 3: Acessibilidade, capacitação e sugestões para a inclusão

Percepção sobre a capacitação profissional para a inclusão
Pedagoga 1 - "Formação dos professores, nós já falamos, nossa também pedagógica é... dos
gestores também, gestores antenados com isso, porque não adianta nada ter a preocupação só do
pedagogo e do professor, o gestor também tem que está motivando pra que isso aconteça, porque
senão...".
Pedagoga 1 - "Nenhuma".
Gestão - "[...]a sala de atendimento é essa formação continuada, os professores recebem esse
atendimento [...]a sala de atendimento vem com uma nova roupagem de oferecer essa formação
continuada é o agendamento, professor vai na sala e agenda um horário que ele tem durante a semana e
ele agenda e tem uma equipe preparada naquele horário pra poder receber [...]".




\begin{abstract}
Professor 5 - “[...] eu entendo que deveria ter primeiro, ter uma capacitação para os professores né, para os técnicos administrativos, para as pessoas né que trabalham na biblioteca acredito que isso seria muito importante e também para o setor que atende diretamente esse aluno, por exemplo restaurante, no caso específico por exemplo do protocolo, ou seja, tem vários setores de atendimento direto a este aluno".

Professor 6 - “[...] eu, por exemplo, sou um exemplo de pessoa que não foi preparado pra receber esse tipo de aluno, a gente foi aprendendo com a convivência e aprender com a convivência, às vezes é ruim pra quem está do outro lado, quem tá tentando aprender".

Intérprete 2 - “[...] Eles não sabem o que fazer, então, a gente pode trabalhar também nesse aspecto de preparação de assistência ao professor, como ele prepara o material, como ele vai adaptar uma aula pro deficiente auditivo, pro aluno surdo, então esse é um ponto também que a gente tem que levar em consideração".

Percepção referente a acessibilidade comunicacional e arquitetônica

Aluno surdo 1 - "Eu já percebi que falta algumas imagens, por exemplo o banheiro, o banheiro só têm escrito banheiro, não sei se é de mulher, se é de homem. Então se fosse sinalizado com algumas imagens".

Aluno surdo 3 -"...eu não tenho acesso como os outros ouvintes, mas aí eu acabo perdendo aquela informação. Então falta assim divulgação, por exemplo se tivesse todo o mês, assim a divulgação parece que é só no começo do ano e aí depois não avisa mais nada então tem quer ter no decorrer do ano informações...".

Professor 6 - "Devido a esses problemas do próprio acompanhamento de ter que dá atenção a mim ao que tá sendo apresentado no programa e ao intérprete a... ele demora mais a entender os conceitos, então quando um determinado assunto tá finalizando aí que eles estão começando a entender"

Percepção das políticas e ações desenvolvidas no IFAM para a inclusão do surdo

Intérprete 1 - "Eu acho assim que a estratégica do IFAM pra dar essa inclusão é o NAPNE, o NAPNE é a estratégia onde eles podem né, é... chegar lá e manifestar as dificuldades que eles estão tendo em sala de aula

Intérprete 2 - "Eu acho que a gente pode citar a questão do treinamento em libras, eu acho que é o que nós estamos fazendo lá no NAPNE é isso".

Professor 6 - "Aqui oficial nós temos o NAPNE né e o... então lá nós temos diversos cursos né, nós temos capacitações, vários projetos de inclusão e eles são é de nível é institucional, ele não atende só o CMC [...]".
\end{abstract}

Fonte: Freitas (2020).

Dessa forma, a partir da contextualização temática das unidades de registro iniciou-se o tratamento dos resultados. Nessa fase realizou-se as inferências e interpretações do conteúdo dos dados que, de acordo Silva e Fossá (2015), deve ser realizada por meio da justaposição das categorias de análise, através da identificação dos aspectos semelhantes e os que outrora foram concebidos como diferentes.

Assim, começou-se o processo de codificação que, segundo Bardin (2016), consiste em uma transformação dos dados brutos levando em conta a representação do conteúdo que esclareça ao analista as características do texto. Silva e Kalhil (2017) descrevem que o processo de codificação envolve a identificação e o registro de elementos do texto que se referem à mesma coisa a fim de relacioná-los e nomeá-los, ou seja, são codificados com um mesmo nome, sendo uma forma de organização do pensamento. 
Dito isto, iniciou-se o processo de codificação das entrevistas, dos registros do diário de campo e rodas de conversa que identificavam ou refletiam a percepção do processo de inclusão escolar, práticas pedagógicas inclusivas e as políticas e ações inclusivas para o aluno surdo.

Dentro desse processo de análise procurou-se descobrir inicialmente nos dados ainda descritivos, o que Bardin (2016) chama de "núcleos de sentido" que fossem significativos e que aparecessem frequentemente na fala dos participantes da pesquisa. Em seguida fez-se o processo de categorização onde reuniu-se grupos de unidades de registro por critérios semânticos que foram agrupados em categorias iniciais, sendo as primeiras impressões do processo de codificação do material analisado. Dessa maneira chegou-se a doze (12) categorias iniciais representadas no quadro 3 , destacado abaixo:

Quadro 3 - Categorias Iniciais

\begin{tabular}{|l|}
\hline \multicolumn{1}{|c|}{ Categorias Iniciais } \\
\hline 1. Percepção da Inclusão escolar \\
\hline 2. Escola inclusiva sinônimo de isolamento \\
\hline 3.Interação e comunicação em libras sinônimo de inclusão escolar \\
\hline 4.Acessibilidade comunicacional como fator preponderante na inclusão de surdos \\
\hline 5.O intérprete como única mediação da relação professor-aluno \\
\hline 6.Integração no planejamento do processo de inclusão escolar \\
\hline 7.Planejamento e avaliação do processo de ensino e aprendizagem do aluno surdo \\
\hline $\begin{array}{l}\text { 8.Acessibilidade pedagógica e adaptação metodológica no processo de ensino e aprendizagem } \\
\text { do aluno surdo }\end{array}$ \\
\hline 9. Capacitação e preparação dos profissionais para a inclusão \\
\hline 10.Acessibilidade comunicacional e arquitetônica para o aluno surdo no IFAM. \\
\hline 11.Percepção das Políticas/ações Inclusivas desenvolvidas no IFAM. \\
\hline 12.Sugestões para a inclusão do aluno surdo no IFAM. \\
\hline
\end{tabular}

Fonte: Freitas (2020).

Com a identificação das categorias iniciais que foram organizadas de forma progressiva, hierárquica e temática, seguiu-se embasados em Silva e Fossá (2015) que orienta o refinamento da análise de dados, agrupando as categorias iniciais em categorias intermediárias identificadas na narrativa dos participantes da pesquisa, na observação direta, além do referencial teórico, com o objetivo de tornar os códigos inicialmente descritivos mais analíticos e teóricos possíveis (SILVA e KALHIL, 2017).

Dessa forma, procurou-se refinar ainda mais os dados por meio de novos agrupamentos das categorias iniciais que apresentavam códigos semelhantes, a fim de conseguir códigos mais analíticos e teóricos que embasassem ainda mais a análise. Feito isso, a partir das doze categorias iniciais estas foram agrupadas em seis categoriais intermediárias identificadas no quadro 4, abaixo. 
Quadro 4 - Seis categorias Intermediárias originadas a partir do agrupamento de doze categorias descritivas iniciais

\begin{tabular}{|c|c|}
\hline Categorias Iniciais & Categorias Intermediárias \\
\hline 1. Percepção da Inclusão escolar & \multirow{2}{*}{$\begin{array}{l}\text { 1. Inclusão Escolar e suas } \\
\text { características }\end{array}$} \\
\hline 2. Escola inclusiva sinônimo de isolamento & \\
\hline $\begin{array}{l}\text { 3. Interação e comunicação em libras sinônimo de inclusão } \\
\text { escolar. }\end{array}$ & \multirow{2}{*}{ 2. O sentido da inclusão escolar } \\
\hline $\begin{array}{l}\text { 4. Acessibilidade comunicacional como fator } \\
\text { preponderante na inclusão de surdos. }\end{array}$ & \\
\hline $\begin{array}{l}\text { 5. O intérprete como única mediação da relação professor- } \\
\text { aluno }\end{array}$ & \multirow{2}{*}{$\begin{array}{l}\text { 3.Planejamento integrado e mediação } \\
\text { em libras }\end{array}$} \\
\hline $\begin{array}{l}\text { 6. Integração no planejamento do processo de inclusão } \\
\text { escolar. }\end{array}$ & \\
\hline $\begin{array}{l}\text { 7. Planejamento e avaliação do processo de ensino e } \\
\text { aprendizagem do aluno surdo. }\end{array}$ & \multirow{2}{*}{$\begin{array}{l}\text { 4. Sistematização do processo de } \\
\text { ensino e aprendizagem do aluno } \\
\text { surdo }\end{array}$} \\
\hline $\begin{array}{l}\text { 8. Acessibilidade pedagógica e adaptação metodológica no } \\
\text { processo de ensino e aprendizagem do aluno surdo. }\end{array}$ & \\
\hline $\begin{array}{l}\text { 9. Capacitação e preparação dos profissionais para a } \\
\text { inclusão }\end{array}$ & \multirow{2}{*}{$\begin{array}{l}\text { 5. Criação de políticas de capacitação } \\
\text { profissional e acessibilidade no } \\
\text { IFAM }\end{array}$} \\
\hline $\begin{array}{l}\text { 10. Acessibilidade comunicacional e arquitetônica para o } \\
\text { aluno surdo no IFAM }\end{array}$ & \\
\hline $\begin{array}{l}\text { 11.Percepção das Políticas/ações Inclusivas desenvolvidas } \\
\text { no IFAM }\end{array}$ & \multirow{2}{*}{$\begin{array}{l}\text { 6. Sistematização de políticas e ações } \\
\text { inclusivas. }\end{array}$} \\
\hline 12.Sugestões para a inclusão do aluno surdo no IFAM & \\
\hline
\end{tabular}

Fonte: Freitas (2020).

Visando a busca de categorias analíticas mais conceituais, procurou-se, de acordo com Silva e Kalhil (2017), reorganizar os códigos em um nível maior de abstração por meio de novas combinações a fim de identificar as categorias analíticas principais ali presentes.

Para isto, realizou-se um processo de refinamento das seis categorias intermediárias realizando novas combinações, reflexões, sistematizações, análises, inferências que resultaram em novos agrupamentos analógicos das categorias intermediárias que nos levaram, após operações progressivas de classificação, a três categorias analíticas finais denominadas: 1.Processo inclusivo e a realidade escolar, 2. A relevância de práticas pedagógicas integradas na inclusão escolar e 3.Políticas e ações para a inclusão escolar do aluno surdo (Quadro 5).

Quadro 5 - Categorias Finais a partir da aglutinação das categorias intermediárias

\begin{tabular}{|l|l|}
\hline \multicolumn{1}{|c|}{ Categorias Intermediárias } & \multicolumn{1}{c|}{ Categorias Finais } \\
\hline I. Inclusão Escolar e suas características & escolar \\
\hline II. O sentido da inclusão escolar & $\begin{array}{l}\text { 2.O A relevância de práticas } \\
\text { pedagógicas integradas na inclusão } \\
\text { escolar. }\end{array}$ \\
\hline $\begin{array}{l}\text { III. Planejamento integrado e o papel do intérprete como } \\
\text { mediador na inclusão }\end{array}$ \\
$\begin{array}{l}\text { IV. Sistematização do processo de ensino e aprendizagem do } \\
\text { aluno surdo }\end{array}$ & \\
\hline
\end{tabular}




\begin{tabular}{|l|l|}
\hline $\begin{array}{l}\text { V. Criação de políticas de capacitação profissional e } \\
\text { acessibilidade no IFAM }\end{array}$ & $\begin{array}{l}\text { 3. Políticas e ações para a inclusão } \\
\text { escolar do aluno surdo. }\end{array}$ \\
\cline { 1 - 2 } VI. Sistematização de políticas e ações inclusivas. & \\
\hline
\end{tabular}

Fonte: Freitas (2020).

\section{CONSIDERAÇÕES FINAIS}

A pesquisa propôs uma reflexão dessa realidade por meio da compreensão de como o processo de inclusão escolar dos alunos surdos estava ocorrendo no IFAM/CMC e constatou, por meio de três categorias analíticas, que o referido processo necessita ser reavaliado e reestruturado, visto que ainda é considerado complexo e desafiador devido a diversas barreiras ainda encontradas dentro da instituição que precisam ser eliminadas por meio do domínio da língua de sinais pelos ouvintes e da língua portuguesa escrita pelos surdos, destacando assim questões de dificuldades de interação, relacionamento e comunicação entre surdos e ouvintes.

Referente a práticas pedagógicas integradas foi possível perceber uma evidente demanda pela sistematização e a efetivação de um processo escolar inclusivo, por meio de um planejamento mais direcionado às peculiaridades do aluno surdo através das adaptações metodológicas necessárias para sua a permanência e êxito nas atividades escolares e que por conseguinte viabilize a acessibilidade pedagógica no contexto da realidade escolar.

Ao longo da pesquisa, ao identificarmos os objetivos e as concepções teóricas percebeuse (embasados também na última categoria descoberta) que a instituição tem desenvolvido (ainda que forma incipiente) políticas e ações para a inclusão escolar, evidenciadas principalmente pelo NAPNE e pelas atividades propostas pelo núcleo referente ao processo inclusivo, mas ao mesmo tempo destaca-se a necessidade de políticas institucionais mais estruturadas de formação docente para a melhoria do processo inclusivo do aluno surdo.

Como obtidos nos resultados da pesquisa (a partir da evidenciação de todas as categorias), a construção do processo inclusivo do aluno surdo foi iniciado e está em andamento, mas ainda precisa de ajustes e reparos para o seu fortalecimento através da transformação de ações inclusivas parciais ou articuladas em ações inclusivas plena e integradas à realidade do contexto escolar da instituição.

A presente pesquisa mostrou que a inclusão escolar do aluno surdo, na escola regular é uma realidade que precisa de acompanhamento juntamente com a capacitação contínua dos profissionais da educação que atuarão com esses alunos, visto que apenas a garantia de uma vaga por meio da matrícula que proporciona a entrada desse aluno na instituição de ensino 
regular não garante o suporte necessário para a sua permanência e êxito, devido aos diversos fatores e questões que perpassam a sua educação no contexto escolar inclusivo.

\section{REFERÊNCIAS}

BARBOSA, Meire Aparecida. Inclusão do surdo no ensino regular: A legislação. 2007. 73

f. Trabalho de Conclusão de Curso. (Faculdade de Filosofia) - Universidade Estadual Paulista, Marília, 2007. Disponível em:

http://www.educadores.diaadia.pr.gov.br/arquivos/File/artigos_edespecial/surdo_sistemaregul ar.pdf. Acessado em 16 nov. 2020.

BRASIL. Lei n ${ }^{\circ}$ 4.024, de 20 de dezembro de 1961. Lei de Diretrizes e Bases da Educação Nacional. Brasília, 1961. Disponível em:

http://www.planalto.gov.br/ccivil_03/leis/L4024.htm. Acesso em 26 out 2020.

BRASIL- Ministério de Educação. Resolução CNE/CEB N 2, de 11 de setembro de 2001. Institui Diretrizes Nacionais para a Educação Especial na Educação Básica. Brasília, 2001. Disponível em: http://portal.mec.gov.br/cne/arquivos/pdf/CEB0201.pdf. Acesso em 26 out 2020.

BRASIL. Ministério da Educação. Secretaria de Educação Especial. Política Nacional de Educação Especial na Perspectiva da Educação Inclusiva. Brasília: MEC/SECAD, 2008. Disponível em:

http://portal.mec.gov.br/index.php?option=com_docman\&view=download\&alias=16690politica-nacional-de-educacao-especial-na-perspectiva-da-educacao-inclusiva05122014\&Itemid=30192. Acesso em 26 out de 2020.

BARDÍN, Laurence. Análise de Conteúdo. $3^{\text {a }}$ ed. São Paulo: Edições 70, 2016.

CRESWELL, John. Investigação qualitativa e projeto de pesquisa: escolhendo entre cinco abordagens. $3^{\text {a }}$. ed. Porto Alegre: Penso, 2014.

GIL, Antônio Carlos. Estudo de Caso: Fundamentação científica subsídios para coleta e análise de dados como dirigir o relatório. $2^{\mathrm{a}}$ ed. São Paulo: Atlas, 2009.

KASSAR, Mônica de Carvalho Magalhães. Educação especial na perspectiva da educação inclusiva: desafios da implantação de uma política nacional. Educar em Revista, Curitiba, s/v. n. 41, p. 61-79, 2011. Disponível em: https://www.scielo.br/pdf/er/n41/05.pdf. Acessado em 16 nov. 2020.

LAKATOS, Eva Maria.; MARCONI, Marina de Andrade. Fundamentos de Metodologia Científica. $7^{\mathrm{a}}$. ed. São Paulo: Atlas, 2010.

LIMA, Eva Lídia Maniçoba de.; NETA, Olívia Morais de Medeiros. Inclusão de pessoas com deficiência visual na educação profissional e tecnológica: Ação TEC NEP e a ação do

NAPNE. In: IV Colóquio Nacional e I Colóquio Internacional. A Produção do Conhecimento em Educação Profissional. Natal, 2017. 
MILLER JUNIOR, Ademar. A inclusão do aluno surdo no Ensino Médio. 2013. 120 f. Dissertação. (Mestrado em Educação) Universidade Federal do Espírito Santo, Vitória, 2013. Disponível em: https://repositorio.ufsc.br/handle/123456789/190443\#: :text=As\%20narrativas\%20dos\%20su jeitos\%20surdos,por\%20meio $\% 20$ da $\% 20$ educa $\%$ C3\% A7\%C3\%A3o\%20especial.. Acessado em 16 nov. 2020.

MOURA, Adriana Borges. Ferro.; LIMA, Maria da Glória Soares Barbosa. A Reinvenção Da Roda: Roda De Conversa: Um Instrumento Metodológico Possível. Revista Temas em Educação, João Pessoa, v.23, n.1, p. 98-106, 2014. Disponível em: https://periodicosonline.uems.br/index.php/interfaces/article/view/448/414. Acessado em 16 nov. 2020.

OLIVEIRA, Katiania Barbosa de. Educação Inclusiva e Formação de Professores no Alto Juruá. 2007. 124 f. Dissertação. (Mestrado em Educação) Universidade Federal do Amazonas, Manaus, 2007. Disponível em: https://tede.ufam.edu.br/bitstream/tede/3169/1/Katiania\%20Barbosa\%20de\%20Oliveira.pdf. Acessado em 16 nov. 2020.

PACHECO, Dalmir. Deficiência e Política Pública: Reflexões sobre humanos invisíveis. $1^{\text {a }}$. ed. São Paulo, Atlas, 2016.

PORLÁN, Rafael; MARTÍN, José. El diario del professor: um recurso para la investigación en el aula. 9a Ed. Sevilia: Díada, 2004.

SANTOS, Marcos Roberto dos. Educação de Surdos: o discurso da inclusão educacional produzido por surdos e ouvintes. 2017. 138 f. Dissertação. (Mestrado em Letras e Artes) Universidade do Estado do Amazonas, Manaus, 2017. Disponível em: http://tede.uea.edu.br/handle/tede/252. Acessado em 16 nov. 2020.

SANTOS, Rogério Augusto dos. Inclusão Escolar: A implementação de uma política de educação inclusiva em um contexto de uma escola pública. 2015. 142 f. Dissertação.

(Mestrado Profissional em Gestão e Avaliação da Educação) Universidade Federal de Juiz de Fora, Juiz de Fora, Minas gerais, 2015. Disponível em: http://mestrado.caedufjf.net/inclusaoescolar-a-implementacao-da-politica-de-educacao-inclusiva-no-contexto-de-uma-escolapublica/. Acessado em 16 nov. 2020.

SÁ, Nelson Pereira de. Escola de Surdos: Avanços, Retrocessos e Realidades. 2011. 223 f. Dissertação. (Mestrado em Educação) Universidade Federal do Amazonas, Manaus, 2011. Disponível em:

https://tede.ufam.edu.br/handle/tede/3237\#: :text=Quanto\%20aos\%20resultados\%2C\%20dest acam\%2Dse,tenham\%20algum\%20conhecimento\%20de\%20Libras. Acessado em 16 nov. 2020.

SILVA, Edna Lúcia da. Metodologia da pesquisa e elaboração de dissertação. $3^{\text {a }}$ Ed. Florianópolis: Laboratório de Ensino a Distância da UFSC, 2001.

SILVA, Andressa Henning.; FOSSÁ, Maria Ivete Trevisan. Análise de Conteúdo: Exemplo de aplicação da técnica para análise de dados qualitativos. Qualit@s Revista Eletrônica, Campina Grande, v.17, n. 1, p.1-14, 2015. Disponível em: 
http://revista.uepb.edu.br/index.php/qualitas/article/view/2113/1403. Acessado em 16 nov. 2020.

SILVA, Cirlande Cabral da.; KALHIL, Josefina. Barrera. A aprendizagem de genética à luz da Teoria Fundamentada: um ensaio preliminar. Ciência \& Educação, Bauru, v.23, n.1, p.125-140, 2017. Disponível em: https://www.scielo.br/scielo.php?pid=S151673132017000100125\&script=sci abstract\&tlng=pt. Acessado em 16 nov. 2020.

SIGOLO, Ana. Regina Lucato.; GUERREIRO, Elaine Maria Bessa. Rebello; CRUZ, Rosangela Aparecida Silva da. Políticas Educacionais para a Educação Especial no Brasil: uma Breve Contextualização Histórica. Práxis Educativa, Ponta Grossa, v.5, n.2, p.173-194, 2010. Disponível em: https://revistas2.uepg.br/index.php/praxiseducativa/article/view/982. Acessado em 16 nov. 2020.

SOUZA, Maria Francisca Nunes de. Política de Educação do Surdo: Problematizando a Inclusão Bilíngue em Escolas Da Rede Municipal de Ensino de Benjamin Constant-AM. 2015. 189 f. Dissertação. (Mestrado em Educação) Universidade Federal do Amazonas, Manaus. 2015. Disponível em: https://tede.ufam.edu.br/handle/tede/4805. Acessado em 16 nov. 2020. 